\title{
Nocturnal oximetry in infants with cystic fibrosis
}

\author{
M P Villa, J Pagani, V Lucidi, S Palamides, R Ronchetti
}

\begin{abstract}
Aim-To investigate whether children with cystic fibrosis under 3 years of age have disordered breathing and episodes of oxygen desaturation during sleep.

Methods-We studied 19 infants ( 9 boys and 10 girls) with cystic fibrosis, mean age 13.1 months (range 3-36 months) and 20 age and sex matched healthy subjects. Patients and controls underwent an overnight polysomnographic study and respiratory function testing on the following morning.

Results-Seven patients with ongoing respiratory tract inflammation had disordered breathing and episodes of oxygen desaturation during sleep. Pulse oximetry showed a significantly lower mean oxygen saturation $\left(\mathrm{SaO}_{2}\right)$ and a higher percentage of total sleep time spent with $\mathrm{SaO}_{2}$ less than $\mathbf{9 3 \%}$ in symptomatic children than in controls.

Conclusion-Results suggest that infants and young children with cystic fibrosis and mild airways inflammation (rhinitis, cough, red throat) have episodes of oxygen desaturation during sleep.

(Arch Dis Child 2001;84:50-54)
\end{abstract}

Keywords: cystic fibrosis; sleep; oxygen desaturation

There have been several reports of severe episodes of arterial oxygen desaturation during sleep in adult and adolescent patients with cystic fibrosis (CF)..$^{1-5}$ Hypoxaemia may be an arousal stimulus that disturbs these patients' normal sleep pattern and their quality of life. Some evidence suggests that nocturnal hypoxaemia plays a role in the pathogenesis of lung damage and cor pulmonale in patients with $\mathrm{CF}^{67} \mathrm{~A}$ number of investigators have suggested that even brief desaturation episodes can increase pulmonary artery pressure. ${ }^{8-10}$

The largest falls in saturation occur during rapid eye movement (REM) sleep and are associated with decreases in tonic electromyographic activity of intercostal muscles and with an irregular respiratory pattern. ${ }^{13-610}$ Ballard et al showed that desaturation episodes during sleep in patients with CF are associated with hypoventilation caused by a reduction in tidal volume and minute ventilation. ${ }^{2}$

Reduced ventilation during REM sleep in adults with $\mathrm{CF}$ has also been described by Tepper et al, who propose that this could account for most of the sleep hypoxaemia in $\mathrm{CF}^{5}$ A decrease in the contribution of the rib cage to tidal volume breathing leads to a decrease in lung volume and to episodes of desaturation. Because desaturation episodes coincided not with obstructive or central apnoeas but with a reduced end expiratory volume during REM sleep they were attributable to airway closure and to the development of underventilated lung regions. To explain the mechanism responsible for sleep induced oxygen desaturation in patients with CF, Muller et al suggest that a cyclic reduction in functional residual capacity (FRC) may determine a ventilation-perfusion mismatch. ${ }^{4}$

The sleep induced changes in oxygenation in patients with CF resemble those reported in adults with chronic bronchitis and chronic obstructive pulmonary disease. ${ }^{11-14}$ In patients with chronic bronchitis and chronic obstructive pulmonary disease the quality of sleep is particularly disturbed in the REM sleep stage..$^{15}$ As most studies to date that have examined ventilation and oxygenation changes during sleep in patients with CF have concentrated on adults and adolescents, we sought to examine these changes in CF patients under 3 years, an age when lung function remains largely unaffected by the disease. We designed this study to investigate whether CF patients less than 3 years of age have disordered breathing and oxygen desaturation during sleep and whether acute respiratory tract inflammation affects ventilation during sleep.

\section{Subjects and methods}

We studied 19 infants and young children (9 boys and 10 girls), mean age 13.1 months (range 3-36 months), referred to our respiratory and sleep laboratory from September 1998 to May 1999 whose CF had been diagnosed before 6 months of age. Patients seen during routine follow up visits at the CF centre of Bambino Gesù and considered clinically well, without acute exacerbation of respiratory symptoms, were scheduled for lung function testing and a sleep study. The interval between clinical assessment and lung function testing ranged from seven to 14 days. In 12 infants CF had been identified between 1 and 2 months following newborn screening ${ }^{17} 18$ and confirmed by three abnormal sweat tests; in seven infants the diagnosis of CF was first suggested by symptoms including meconium ileus $(n=1)$, meconiun peritonitis $(n=1)$, metabolic acidosis $(n=1)$, diarrhoea and vomiting with poor growth $(n=2)$, and bronchial asthma ( $\mathrm{n}=1)$ and confirmed by three abnormal sweat tests. As a control group we studied 20 age and sex matched healthy subjects.

Patients with $\mathrm{CF}$ and controls underwent clinical assessment, a polysomnographic study, and lung function testing on the following morning. When studied, seven children had symptoms compatible with mild respiratory tract inflammation - that is, rhinorrhoea, cough, and red throat. At the time of the study 
Table 1 Anthropometric variables in children with cystic fibrosis

\begin{tabular}{|c|c|c|c|c|c|}
\hline Subject no. (sex) & Age (mth) & $\begin{array}{l}\text { Weight } \\
\text { (centile) }\end{array}$ & $\begin{array}{l}\text { Height } \\
\text { (centile) }\end{array}$ & $\begin{array}{l}\text { Diagnosis } \\
\text { (type) }\end{array}$ & $\begin{array}{l}\text { Inflammatory } \\
\text { indext }\end{array}$ \\
\hline \multicolumn{6}{|c|}{ Symptomatic* $(n=7)$} \\
\hline $1(\mathrm{~F})$ & 18 & 77 & 97 & Screening & 1.99 \\
\hline $2(\mathrm{~F})$ & 10 & 80 & 90 & Screening & 4.8 \\
\hline $3(\mathrm{M})$ & 7 & 25 & 90 & Screening & 6.8 \\
\hline $4(\mathrm{M})$ & 7 & 60 & 25 & Symptoms & 8.5 \\
\hline $5(\mathrm{~F})$ & 5 & 3 & 3 & Symptoms & 7.2 \\
\hline $6(\mathrm{~F})$ & 13 & 80 & 25 & Symptoms & 0.92 \\
\hline $7(\mathrm{~F})$ & 7 & 25 & 50 & Screening & 5.14 \\
\hline Mean (SD) & $9.6(4.5)$ & $50(31.8)$ & $54(38.6)$ & & $5.1(2.8) \ddagger$ \\
\hline \multicolumn{6}{|c|}{ Asymptomatic $^{*}(n=12)$} \\
\hline $8(\mathrm{M})$ & 6 & 25 & 25 & Screening & 0.0 \\
\hline $9(\mathrm{M})$ & 3 & 80 & 90 & Screening & 0.0 \\
\hline $10(\mathrm{~F})$ & 36 & 97 & 80 & Symptoms & 0.6 \\
\hline $11(\mathrm{M})$ & 25 & 27 & 50 & Screening & 2.4 \\
\hline $12(\mathrm{~F})$ & 9 & 30 & 50 & Screening & 6.6 \\
\hline $13(\mathrm{M})$ & 30 & 12 & 4 & Screening & 1.2 \\
\hline $14(\mathrm{~F})$ & 5 & 50 & 75 & Symptoms & 7.2 \\
\hline $15(M)$ & 32 & 3 & 3 & Symptoms & 2.6 \\
\hline $16(\mathrm{M})$ & 15 & 50 & 90 & Symptoms & 0.0 \\
\hline $17(\mathrm{~F})$ & 6 & 50 & 50 & Screening & 0.0 \\
\hline $18(\mathrm{M})$ & 6 & 3 & 3 & Screening & 1.9 \\
\hline $19(\mathrm{~F})$ & 9 & 50 & 10 & Screening & 0.0 \\
\hline Mean (SD) & $15.2(12.1)$ & $39.7(29)$ & $47.7(33.7)$ & & $1.8(2.5)$ \\
\hline \multicolumn{6}{|l|}{ Total subjects } \\
\hline Mean (SD) & $13.1(10.2)$ & $43.5(29.6)$ & $50.4(34.4)$ & & $3.1(3.0)$ \\
\hline
\end{tabular}

Statistical analysis used two tailed $t$ test.

${ }^{\star}$ Clinical condition on testing with or without symptoms of respiratory inflammation.

†Number of exacerbations per month $\times 12$.

$\ddagger \mathrm{p}=0.02$ versus asymptomatic.

no abnormal findings were shown on chest $x$ ray in any patient

We reviewed each child's respiratory history to assess the number of respiratory tract infections during life, normalised for age (inflammatory index: number of pulmonary exacerbations per month of life $\times 12$ ). ${ }^{19}$

Parents gave informed consent for their children to take part in the study; none of the procedures were invasive or traumatic.

\section{POLYSOMNOGRAPHIC STUDY}

Polysomnograms were recorded with a Medilog SAC 800-Oxford apparatus, in 16 infants during the night (between 2100 and 0600), and in three during the afternoon (between 1400 and 1800). No infant had sleep pharmacologically induced or was sleep deprivated. Polysomnographic recordings included the following channels: electroencephalogram (C3-A2; C4-A1) recorded through surface electrodes attached to the scalp; electrooculogram; and electromyography (submental and exterior tibial). All variables were monitored continuously and were used to determine sleep stages according to the criteria of Rechtschaffen and Kales. ${ }^{20}$ Chest and abdominal respiratory movements were determined by impedance plethysmography; nasal and mouth air flows were recorded by thermocouples placed near the nostrils and the mouth. $\mathrm{SaO}_{2}$ was monitored by finger pulse oximetry; we defined oxygen desaturation as a $4 \%$ fall from baseline oxygen values. We calculated total sleep time (TST), and the sleep time spent with oxygen saturation lower than $93 \%, 90 \%$, and $85 \%$. The mean low $\mathrm{SaO}_{2}$ and the lowest $\mathrm{SaO}_{2}$, and the duration of desaturation episodes were also measured. The electrocardiogram was recorded through precordial electrodes. Polysomnographic studies took place in the sleep laboratory, a comfortable temperature controlled $\left(21-22^{\circ} \mathrm{C}\right)$ room equipped to allow children and parents to sleep together.

We defined sleep disordered breathing as follows: apnoea index $>1$ event $/ \mathrm{h}$, apnoea + hypopnea index $>5$ events $/ \mathrm{h}$, mean low $\mathrm{SaO}_{2}$ $<90 \%$, and lowest $\mathrm{SaO}_{2}<85 \%$.

Respiratory function was studied (Sensor Medics 2600 equipment) during quiet sleep induced by chloral hydrate $(50 \mathrm{mg} / \mathrm{kg})$ in patients and in 14 age and sex matched healthy subjects. Partial flow-volume curves were obtained by the chest compression technique. In brief, an inflatable plastic bag was wrapped around the infant's abdomen. The bag pressure was increased in increments of $5-10 \mathrm{~cm}$ water from a minimum of 20 to a maximum of $70 \mathrm{~cm}$ water. On each occasion, the inflation of the bag was begun at end tidal inspiration and maintained until a spontaneous inspiratory effort was evident or no additional airflow could be obtained. The maximal pressure applied was that which produced no further increase in flow at the end tidal expiration point (functional residual capacity, FRC). This manoeuvre was performed three to five times in each infant, and the greatest flow obtained at the end tidal expiration point $\left(\mathrm{V}_{\max }\right.$ FRC) was used in the analyses. We also calculated the expiratory time constant (TC). Compliance and resistance of the respiratory system was determined with the method of single occlusion, evoking the Hering-Breuer reflex to bring on a passive expiration. FRC was measured by the nitrogen washout method $\left(\mathrm{FRC}_{\mathrm{N} 2}\right)$ by the $\mathrm{N}_{2}$ dilution technique using $100 \%$ oxygen, a mixing chamber, and a fast $\mathrm{N}_{2}$ analyser $(>50$ ms) (Giesler tube).

STATISTICAL ANALYSIS

Data are expressed as mean (SD). Student's $t$ tests for independent data (univariate analysis) were used to compare continuous variables in patients and control subjects. The Pearson correlation was used to evaluate the association between $\mathrm{SaO}_{2}$ and respiratory function. Multiple regression analysis was used to determine the importance of these variables in determining desaturation during sleep. Probability values equal to or less than 0.05 were considered statistically significant.

\section{Results}

Sixteen of those studied had grown normally and three infants were on the 3 rd percentile for weight and height (table 1).

When tested, seven infants (two boys and seven girls) had mild respiratory symptoms (runny nose, cough, and red throat), and 12 (seven boys and five girls) were asymptomatic. Symptomatic infants had a significantly higher inflammatory index than asymptomatic infants (5.1 (2.8) $v 1.8(2.5) ; \mathrm{p}<0.01)$. Five symptomatic $(5 / 7 ; 71 \%)$ and two asymptomatic subjects $(2 / 12 ; 17 \%)$ had an inflammatory index greater than 4 . In $4 / 7$ symptomatic $(57 \%)$ and $8 / 12$ asymptomatic infants $(66 \%)$ $\mathrm{CF}$ was diagnosed at newborn screening.

No difference was found between the sleep architecture of patients with CF or control subjects $(\mathrm{REM}=27.0(19.1) \%$ v $28.0(9.6) \%)$. 
Table 2 Polysomnographic variables: comparison of patients with cystic fibrosis (symptomatic and asymptomatic) and controls

\begin{tabular}{|c|c|c|c|c|c|c|c|c|c|}
\hline \multirow[b]{2}{*}{ Subjects } & \multicolumn{9}{|c|}{ Polysomnographic variables } \\
\hline & $\begin{array}{l}\text { Apnoea }+ \\
\text { hypopnoea index } \\
\text { (events } / h \text { ) }\end{array}$ & $\begin{array}{l}\text { Apnoea } \\
\text { index } \\
\text { (events } / h \text { ) }\end{array}$ & $\begin{array}{l}\text { Mean } \mathrm{SaO}_{2} \\
(\%)\end{array}$ & $\begin{array}{l}\text { Lowest } \mathrm{SaO}_{2} \\
(\%)\end{array}$ & $\begin{array}{l}\text { Sleep time with } \\
\mathrm{SaO}_{2}<93 \\
(\%)\end{array}$ & $\begin{array}{l}\mathrm{Mean} \mathrm{SaO}_{2} \\
(\mathrm{NREM}) \\
(\%)\end{array}$ & $\begin{array}{l}\mathrm{Mean} \mathrm{SaO}_{2} \\
(\mathrm{REM}) \\
(\%)\end{array}$ & $\begin{array}{l}\text { Lowest } \mathrm{SaO}_{2} \\
(\mathrm{NREM}) \\
(\%)\end{array}$ & $\begin{array}{l}\text { Lowest } \mathrm{SaO}_{2} \\
(\mathrm{REM}) \\
(\%)\end{array}$ \\
\hline Symptomatict $(\mathrm{n}=7)$ & $4.2(5.6)$ & $1.9(2.8)$ & $94.1(2.6)^{\star \star \star}$ & $81.7(5.7)^{\star \star}$ & $10.1(12.2)^{\star \star \star}$ & $94.7(1.5)^{\star \star}$ & $93.5(1.9)$ & $88.5(2.6)$ & $84.0(4.7)$ \\
\hline Asymptomatict $(n=12)$ & $4.6(11.1)$ & $0.9(1.2)$ & $96.5(1.0)$ & $88.9(6.6)$ & $2.1(4.1)$ & $96.0(1.1)$ & $96.0(1.4)$ & $87.4(6.4)$ & $88.0(8.4)$ \\
\hline Total patients $(\mathrm{n}=19)$ & $4.44(9.3)$ & $1.3(2.0)$ & $95.6(2.1)^{\star \star}$ & $85.9(7.0)^{\star}$ & $5.0(8.5)^{\star}$ & $95.4(1.4)^{\star}$ & $94.7(2.0)$ & $87.8(5.0)$ & $86.0(6.7)$ \\
\hline Controls $(n=20)$ & $4.9(3.1)$ & $1.0(0.7)$ & $96.9(1.1)$ & $89.1(5.2)$ & $1.0(3.1)$ & $96.3(0.9)$ & $95.0(19.7)$ & $90.0(4.8)$ & $88.2(19.1)$ \\
\hline
\end{tabular}

Data expressed as mean (SD). Statistical analysis used two tailed $t$ test. ${ }^{\star} \mathrm{p}<0.05 v$ controls; ${ }^{\star \star} \mathrm{p}<0.001 v$ controls; ${ }^{\star \star \star} \mathrm{p}<0.0001 v$ controls. $\nmid$ Clinical condition at the moment of the test with or without symptoms of respiratory inflammation.

Symptomatic subjects spent a smaller percentage of the total sleep time in REM sleep than controls $\quad(16.9 \quad(8.7) \% \quad v \quad 28.0 \quad(9.6) \%$; $\mathrm{p}<0.001)$. Symptomatic and asymptomatic patients had normal apnoea indexes (number of apnoeas per hour of sleep) and normal apnoea + hypopnoea indexes (table 2 ).

In asymptomatic patients and controls, pulse oximetry showed no significant differences in mean oxygen saturation, mean lowest oxygen saturation, or percentage of total sleep time spent with $\mathrm{SaO}_{2}$ less than $93 \%$. Symptomatic patients had significantly lower mean oxygen saturation than controls $(p<0.0001)$. In symptomatic patients, the mean oxygen saturation in REM sleep was lower than in non-REM (NREM) sleep. The percentage of sleep time spent with $\mathrm{SaO}_{2}$ less than $93 \%$ was higher in symptomatic children than in controls $(\mathrm{p}<0.0001)$. The percentage of sleep time spent with $\mathrm{SaO}_{2}$ less than $90 \%$ and $85 \%$ was higher in symptomatic than in asymptomatic patients. The lowest $\mathrm{SaO}_{2}$ values were lower in symptomatic patients than in controls $(\mathrm{p}<0.001)$. Sleep disordered breathing was shown in all seven symptomatic patients, but in no asymptomatic patients or control subjects.

No differences were found in polysomnographic variables in patients diagnosed by screening or by symptoms. Lung function testing (table 3 ) showed a higher respiratory rate in symptomatic than in control subjects $(\mathrm{p}<0.01)$. Values for compliance and resistance of the respiratory system came within normal ranges and no significant differences emerged between the symptomatic and asymptomatic groups and controls. $\mathrm{FRC}_{\mathrm{N} 2}$ values did not differ significantly in patients or in controls. Plethysmography yielded a significantly lower mean $\mathrm{V}_{\max } \mathrm{FRC}$ in the symptomatic than in the control group $(p<0.001)$.

Pearson's correlation between the respiratory function variables and polysomnographic variables and clinical findings showed that respiratory frequency correlated with the mean low $\mathrm{SaO}_{2}$ during sleep $(r=-0.592 ; \mathrm{p}<0.05)$, and the $\mathrm{FRC}_{\mathrm{N} 2}$ values correlated with the number of respiratory exacerbations (inflammatory index $)(r=-0.593 ; \mathrm{p}<0.05)$.

Multiple regression among the dependent variables (mean $\mathrm{SaO}_{2}$, clinical findings) and the clinical and respiratory function variables (respiratory rate, compliance and resistance of the respiratory system, $\mathrm{V}_{\max } \mathrm{FRC}, \mathrm{FRCN}_{2}$, and TC) identified the variables most likely to be associated with desaturation during sleep as the presence of respiratory symptoms during testing $(p<0.001)$ and higher TC values $(\mathrm{p}<0.01)$.

\section{Discussion}

Of the $19 \mathrm{CF}$ infants and children less 3 years of age, only the seven with ongoing respiratory tract inflammation had sleep disordered breathing and oxygen desaturation during sleep. Even in normal individuals sleep induces changes in the respiratory pattern, ${ }^{21}$ consisting of a reduction in lung volume and minute ventilation..$^{22-25}$ Whereas these changes have no metabolic consequences in children with healthy lungs, in children with chronic lung disease they can provoke ventilatory anomalies and oxygen desaturation episodes. ${ }^{26}$

In infants and young children such as those studied, ventilatory mechanics differ from those in children and adolescents. The shape of a young infant's rib cage, for example, is unlike that of an adult. Owing to the horizontal insertion of the ribs and the position of the diaphragm in infancy, the rib cage is more compliant and the lung is mechanically less efficient. Increased rib cage compliance and higher respiratory resistance are partly responsible for respiratory events during sleep. In addition, the respiratory muscle hypotonia that characterises the REM sleep stage favours and aggravates the nocturnal hypoventilation typical of obstructive lung diseases.

The normal sleep induced fall in FRC, which may drop even to $40 \%$ of the baseline value in some sleep stages, ${ }^{27}$ reduces $\mathrm{O}_{2}$ reserve. These effects become even more apparent if the fall in FRC coincides with the paradoxical breathing ${ }^{28}$ characteristic of newborn babies

Table 3 Respiratory function: comparison of patients with cystic fibrosis (symptomatic and asymptomatic) and controls

\begin{tabular}{lllllll}
\hline Subjects & $\begin{array}{l}\text { Respiratory rate } \\
\text { (breaths/min) }\end{array}$ & $\begin{array}{l}\text { Compliance } \\
(\mathrm{mllcm} \mathrm{H} \mathrm{O} / \mathrm{kg})\end{array}$ & $\begin{array}{l}\text { Resistance } \\
\left(\mathrm{cm} \mathrm{H} \mathrm{H}_{2} \mathrm{O} / \mathrm{ml} / \mathrm{s}\right)\end{array}$ & $\begin{array}{l}F R C_{N 2} \\
(\%)\end{array}$ & $\begin{array}{l}V_{\text {max }} \text { FRC } \\
(\%)\end{array}$ & $\begin{array}{l}\text { Time constant } \\
(\mathrm{s})\end{array}$ \\
\hline Symptomatict $(\mathrm{n}=7)$ & $41.8(12.2)^{\star}$ & $1.22(0.4)$ & $0.04(0.01)$ & $98.6(11.4)$ & $57.4(24.0)^{\star \star}$ & $0.41(0.19)$ \\
Asymptomatict $(\mathrm{n}=12)$ & $32.8(8.4)$ & $1.40(0.4)$ & $0.04(0.01)$ & $112.8(24.5)$ & $77.2(37.3)$ & $0.31(0.15)$ \\
Total patients (n=19) & $36.3(10.7)$ & $1.33(0.4)$ & $0.04(0.01)$ & $106.8(20.6)$ & $61.9(32.8)^{\star}$ & $0.35(0.17)$ \\
Controls (n = 14) & $31.9(9.2)$ & $1.43(0.5)$ & $0.04(0.01)$ & $101.7(28)$ & $103.4(37.3)$ & $0.34(0.26)$ \\
\hline
\end{tabular}

Data expressed as mean (SD). Statistical analysis used two tailed $t$ test.

${ }^{\star} \mathrm{p}<0.01 v$ controls; ${ }^{\star \star} \mathrm{p}<0.001 v$ controls.

†Clinical condition at the moment of the test with or without symptoms of respiratory inflammation. 
and infants with chronic lung diseases. These conditions predispose subjects with compromised lung mechanics to a sleep induced fall in $\mathrm{O}_{2}$.

When respiratory tract inflammation intervenes, respiratory system resistance and hypoventilation may increase, thus inducing desaturation during sleep. This is presumably what happened in our symptomatic patients. Polysomnograms showed that the symptomatic subjects spent more sleep time with $\mathrm{SaO}_{2}$ less than $93 \%$ than controls $(\mathrm{p}<0.0001)$. In addition, they spent more sleep time with desaturation $\left(\mathrm{SaO}_{2}\right.$ less than $\left.90 \%\right)$. They also had lower mean $\mathrm{SaO}_{2}$ during sleep $(\mathrm{p}<0.001)$. Our observations refer exclusively to noncomplicated respiratory tract infections. None of the infants we studied had severe pulmonary exacerbations or fever, neither did they have clinical evidence of infection or abnormal chest $x$ ray findings.

In a study conducted in 1983 in adolescent CF patients, Tepper et al showed that episodes of arterial oxygen desaturation occurred chiefly during REM sleep. ${ }^{5}$ REM sleep worsened sleep induced respiratory changes, including hypoventilation, and increased the variability of the sleep pattern. The desaturation episodes coincided strictly with reduced minute ventilation. Our data agree with the observation of Tepper et al of lower $\mathrm{SaO}_{2}$ values in REM than in NREM sleep, but only in subjects with respiratory symptoms.

In a study comparing nocturnal hypoxia with lung function values, Stokes et al observed smaller $\mathrm{SaO}_{2}$ changes in patients with moderate to severe illnesses $\left(\mathrm{FEV}_{1}=31-63 \%\right.$ of the predicted value) than in patients with severe illnesses $\left(\mathrm{FEV}_{1}=17 \%\right.$ of the predicted value $) .{ }^{29}$ In adults, as Pond and Conway have shown, ${ }^{30}$ low $\mathrm{FEV}_{1}$ values may be useful in identifying patients at risk for nocturnal hypoxaemia, even though no predictive cut off value has been defined for $\mathrm{FEV}_{1}$.

Except for the significantly lower $\mathrm{V}_{\max } \mathrm{FRC}$ in children who were symptomatic when tested, our 19 patients had normal lung function values. In a study of $\mathrm{CF}$ infants without respiratory symptoms, Beardsmore et al concluded that flow-volume curves do not disclose lung dysfunction at this young age. ${ }^{31}{ }^{32}$ Our lung function findings confirm this conclusion. Apart from the correlation between respiratory frequency and mean $\mathrm{SaO}_{2}$ during sleep, we found no correlation between oxygen saturation and lung function variables in our patients. One reason could be that CF first reduces alveolar ventilation and only later affects lung function variables, as Coates et al have proposed. ${ }^{33}$ More subtle anomalies such a change in the ventilation/perfusion ratio would be better revealed by more sensitive methods, including lung scintigraphy, than by lung function tests. Sleep could be a challenge that triggers these anomalies. An interesting finding in our study is that even in CF patients younger than 3 years, pulmonary exacerbations can alter lung function, reducing $\mathrm{V}_{\max }$ FRC.

It is known that infants with $\mathrm{CF}$ already have airways inflammation, even in the absence of acute infections. ${ }^{33-37}$ Tepper et al have proposed that this inflammation helps to aggravate the lower respiratory tract infections that develop early in life and may be responsible for airways obstruction. ${ }^{38}$ Our data are in total agreement, showing mild airway inflammation and signs of obstruction in early months of life, as shown by the low $\mathrm{V}_{\text {max }}$ FRC values and high TC values on the flow-volume curves.

In the multiple regression including all the polysomnographic, clinical, and respiratory variables studied we identified two variables as risk factors for nocturnal desaturation: respiratory symptoms and higher TC values. In addition, we found lower FRC values in patients who had more pulmonary exacerbations. Another predisposing factor for nocturnal desaturation was a high respiratory rate, an expression of possible lung impairment. Accordingly, subjects who had higher respiratory rates also had lower $\mathrm{SaO}_{2}$ values during sleep. Infants who had respiratory symptoms when tested were mainly (5/7) also those who had more pulmonary exacerbations. Hence CF infants with more severe clinical disease may be those who have nocturnal desaturation.

Repeated episodes of nocturnal hypoxia are a stimulus for the development of pulmonary hypertension..$^{1-3689}$ Nevertheless definitive data are lacking on the natural history of sleep induced hypoxia and its role in the pathogenesis of cor pulmonale. If hypoxic stimuli begin at such an early age, their consequences could be more severe. Hence the importance of assessing the severity and duration of hypoxia even at this age.

We conclude that infants with CF in whom mild airways inflammation develops during the first months of life have episodes of oxygen desaturation during sleep. Hence these children may benefit from nocturnal $\mathrm{SaO}_{2}$ monitoring. Controlled studies are needed to determine the usefulness of $\mathrm{O}_{2}$ supplementation for sleep induced respiratory symptoms.

1 Francis PW, Muller NL, Gurwitz D, et al. Hemoglobin desaturation-its occurrence during sleep in patients with cystic fibrosis. Am $\mathcal{F}$ Dis Child 1980;134:734-40.

2 Ballard RD, Sutarik JM, Clover CW, et al. Effects of non-REM sleep on ventilation and respiratory mechanics in adults with cystic fibrosis. Am $\mathcal{F}$ Respir Crit Care Med 1996;153:266-71.

3 Mansell AL. Sleep hypoxemia in patients with cystic fibrosis. Am f Dis Child 1980;134:733.

4 Muller NL, Francis PW, Gurwitz D, et al. Mechanism of hemoglobin desaturation during rapid eye movement sleep in normal subjects and in patients with cystic fibrosis. $A m$ Rev Respir Dis 1980;121:463-9.

5 Tepper RS, Skatrud JB, Dempsey JA. Ventilation and oxygenation changes during sleep in cystic fibrosis. Chest

6 Spier S, Rivlin J, Hughes D, et al. The effect of oxygen on sleep, blood gases and ventilation in cystic fibrosis. Am Rev Respir Dis 1984;129:712-18.

7 Block AJ, Boysen PG, Wynne JW. The origins of cor pulmonale; a hypothesis. Chest 1979;75:109-10.

8 Regnis JA, Piper AJ, Henke KG, et al. Benefits of nocturnal nasal CPAP in patients with cystic fibrosis. Chest 1994;106: $1717-24$.

9 Boysen PG, Block AJ, Wynne JW. Nocturnal pulmonary hypertension in patients with chronic obstructive pulmonary disease. Chest 1979;76:536-42.

10 Unger M, Atkins M, Briscoe WA, et al. Potentiation of pulmonary vasoconstrictor response with repeated intermittent hypoxia. $\mathcal{F}$ Appl Physiol 1977;43:662-7.

11 Douglas NJ, Calverley PM, Legget J, et al. Transient hypoxemia during sleep in chronic bronchitis and emphysema. Lancet 1979;1:1-4.

12 Wynne JW, Block AJ, Hemenway J, et al. Disordered breathing and oxygen desaturation during sleep in patients with
chronic obstructive lung disease (COLD). Am f Med 1979; 66:573-9. 
13 Kearley R, Wynne JW, Block AJ, et al. The effect of low flow oxygen on sleep disordered breathing and oxygen desaturation. A study of patients with chronic obstructive lung disease. Chest 1980;78:682-5.

14 Guilleminault C, Cummiskey J, Motta J. Chronic obstructive airflow disease and sleep studies. Am Rev Respir Dis 1980;122:397-406.

15 Calverley PM, Brezinova V, Douglas NJ, et al. The effect of oxygenation on sleep quality in chronic bronchitis and emphysema. Am Rev Respir Dis 1982;126:206-10.

16 Fleetham J, West P, Mezon B, et al. Sleep, arousals and oxygen desaturation in chronic obstructive pulmonary disease. 429-33.

17 Cassio A, Bernardi F, Piazzi S, et al. Neonatal screening for cystic fibrosis by dried blood trypsin assay. Results in 47.127 newborn infants from a homogeneous population. Acta Paediatr Scand 1984;73:554-8.

18 Dankert-Roelse JE, te Meerman GJ. Long term prognosis of patients with cystic fibrosis in relation to early detection by patients with cystic fibrosis in relation to early detection by Thorax 1995;50:712-18.

19 Ramsey BW, Gore EJ, Smith AL, et al. The effect of respiratory viral infections on patients with cystic fibrosis. $A m \mathcal{F}$ Dis Child 1989;143:662-8.

20 Rechtschaffen A, Kales A. A manual of standardized terminology, techniques and scoring system for sleep states of human subjects, 1st edn. Washington, DC: National Institutes of Health Publications, 1968 .

21 Loughlin GM, Carroll JL. Sleep and respiratory disease in children. In: Ferber R, Kryger M, eds. Principles and practice of sleep medicine in the child. Philadelphia: WB Saunders, 1995;217-30.

22 Henderson-Smart DJ, Read DJ. Reduced lung volume during behavioral active sleep in the newborn. 7 Appl Physiol 1979;46:1081-5.

23 Beardsmore CS, MacFadyen UM, Moosavi SS, et al. Measurement of lung volumes during active and quiet Measurement of lung volumes during active

24 Moriette G, Chaussian M, Radvanyi-Bouvet MF, et al. Functional residual capacity and sleep states in the premaFunctional residual capacity and sleep states

25 Walti H, Moriette G, Radvanyi-Bouvet MF, et al. Influence of breathing pattern on functional residual capacity in sleeping newborn infants. $\mathcal{F}$ Dev Physiol 1986;8:167-72.
26 Allen MB, Mellon AF, Simmonds EJ, Page RL, Littlewood JM. Changes in nocturnal oximetry after treatment of
exacerbations in cystic fibrosis. Arch Dis Child 1993;69: exacerbation 201 .

27 Hudgel DW, Devadatta P. Decrease in functional residual capacity during sleep in normal humans. 7 Appl Physiol 1984;57:1319-22.

28 Gaultier C, Praud JP, Canet E, et al. Paradoxical inward rib cage motion during rapid eye movement sleep in infants and young children. $\mathcal{F}$ Dev Physiol 1987;9:391-7.

29 Stokes DC, McBride JT, Wall MA, et al. Sleep hypoxemia in young adults with cystic fibrosis. Am $\mathcal{F}$ Dis Child 1980;134: 741-3.

30 Pond MN, Conway SP. Nocturnal oxygen desaturation and spirometric parameters in adults with cystic fibrosis. Thorax 1995;50:539-42.

31 Beardsmore CS, Bar-Yishay E, Maayan C, et al. Lung function in infants with cystic fibrosis. Thorax 1988;43:545-51.

32 Tepper RS, Hiatt P, Eigen $\mathrm{H}$, et al. Infants with cystic fibrosis: pulmonary function at diagnosis. Pediatr Pulmonol $1988 ; 5: 15-18$

33 Coates AL, Boyce P, Shaw DG, et al. The relationship between the chest radiograph, regional lung function studies, exercise tolerance and clinical condition in cystic fibrosis. Arch Dis Child 1981;56:106-11.

34 Eigen H, Rosenstein BJ, FitzSimmons S, et al. A multicenter study of alternate-day prednisone therapy in patients with cystic fibrosis. Cystic Fibrosis Foundation Prednisone Trial Group. F Pediatr 1995;126:515-23.

35 Khan TZ, Wagener JS, Bost T, et al. Early pulmonary inflammation in infants with cystic fibrosis. Am $\mathcal{F}$ Respir Crit Care Med 1995;151:1075-82.

36 Richman-Eisenstat JB, Jorens PG, Herbert CA, et al. Interleukin-8: an important chemoattractant in sputum of patients with chronic inflammatory airway diseases. $A m \mathcal{F}$ Physiol 1993;264:L413-18.

37 van Haren EH, Lammers JW, Festen J, et al. The effects of the inhaled corticosteroid budesonide on lung function and bronchial hyperresponsiveness in adult patients with cystic fronchial hyperresponsiveness in adult

38 Tepper RS, Eigen H, Stevens J, et al. Lower respiratory illness in infants and young children with cystic fibrosis: evaluation of treatment with intravenous hydrocortisone. Pediatr Pulmonol 1997;24:48-51. 